Running Head: MOTIVATIONAL PROSODY

You 'have' to hear this: Using tone of voice to motivate others

Netta Weinstein ${ }^{1}$, Konstantina Zougkou ${ }^{2}$, and Silke Paulmann ${ }^{2}$

${ }^{1}$ Cardiff University ${ }^{2}$ University of Essex

${ }^{1}$ Address correspondence to:

Netta Weinstein

70 Park Place

Cardiff, UK CF10 3FT

WeinsteinN@cardiff.ac.uk 


\begin{abstract}
The present studies explored the role of prosody in motivating others, and applied selfdetermination theory (Ryan \& Deci, 2000) to do so. Initial studies describe patterns of prosody that discriminate motivational speech. Autonomy support was expressed with lower intensity, slower speech rate and less voice energy in both motivationally laden and neutral (but motivationally primed) sentences. In a follow-up study, participants were able to recognize motivational prosody in semantically neutral sentences, suggesting prosody alone may carry motivational content. Findings from subsequent studies also showed that an autonomy-supportive as compared to a controlling tone facilitated positive personal (perceived choice and lower perceived pressure, well-being) and interpersonal (closeness to others and prosocial behaviors) outcomes commonly linked to this type of motivation. Results inform both the social psychology (in particular motivation) and psycholinguistic (in particular prosody) literatures and offer a first description of how motivational tone alone can shape listeners' experiences.
\end{abstract}

Keywords: self-determination theory; autonomy support; controlling motivation; motivational prosody; social prosody; prosodic contour

Public Significance: These studies highlight that tone of voice can be used to motivate others, even in the absence of motivation-specific words. In doing so, they characterize two types of motivation we know to be important to well-being and behavior: autonomy-support and control. They show that tone of voice alone can change listeners' experience in predictable ways, with autonomysupport increasing listeners' well-being and sociability compared to control. 


\section{You 'have' to hear this: Using tone of voice to motivate others}

Motivational language is a significant aspect of daily interactions. A child may be told to "go and tidy your room", or a health care provider may argue that "it is important that you take this medication". While the verbal message plays an important role in shaping behavior, there is reason to believe that prosody is also critical; for example, listening to a calm but firm tone of voice saying "go and tidy your room" will have greater impact on children's behavior than listening to the same words spoken in a shaky, low tone of voice. Through four studies, this paper explores how strategies of motivating others are expressed and experienced through prosody.

This work is informed by self-determination theory (SDT; Deci \& Ryan, 1987; Ryan \& Deci, 2000), which argues that two types of motivationally-rich environments can drive behavior, autonomy support and control. Compared to autonomy-supportive environments, controlling ones undermine feelings of being supported in choice and self-expression, and increase feeling pressured and coerced (Soenens \& Vansteenkiste, 2010). This can happen through motivators' behaviors; to be autonomy supportive they can provide choices, meaningful explanations for rules and guidelines, or take an interest in the perspectives of those they inspire to action (Reeve, 2009; Reeve \& Jang, 2006; Reeve, Jang, Hardre, \& Omura, 2002). Motivation can also be shaped by words. For instance, saying "you may [do this] if you choose" supports self-initiation and psychological freedom. In contrast, controlling statements such as "you must [do this]" attempt to energize others through pressure which stifles self-expression (Barber, 1996; Soenens \& Vansteenkiste, 2010). Autonomysupportive messages are more reliably effective in promoting attention and participation (Reeve, Jang, Carrell, Jeon, \& Barch, 2004), and behavioral engagement in the long-term (e.g., Black \& Deci, 2000; Gagné, 2003; Vansteenkiste, Simons, Lens, Sheldon, \& Deci, 2004).

\section{Benefits of Autonomy support over Control}

Autonomy-supportive versus controlling environments have also been shown, in 
experimental and correlational research and cross-culturally, to improve well-being, increasing happiness and self-esteem (Gagné, 2003b; O'Rourke, Smith, Smoll, \& Cumming, 2012; Reis, Sheldon, Gable, Roscoe, \& Ryan, 2000; Vansteenkiste \& Ryan, 2013), energy and vitality (Ryan \& Frederick, 1997), and life satisfaction (e.g., Sheldon \& Elliot, 1999). Being in autonomy-supportive climates also has relational consequences. Those who receive autonomy support experience more interpersonal closeness (Knee, Hadden, Porter, \& Rodriguez, 2013; Vansteenkiste, Ryan, \& Deci, 2008), empathy and caring (e.g., Weinstein, Hodgins, \& Ryan, 2010), and perform better on relational tasks (Jõesaar, Hein, \& Hagger, 2011; Vansteenkiste et al., 2004). These effects are observed across multiple domains and relationship types. For example, in parent-child relationships (e.g., Grolnick, Gurland, DeCourcey, \& Jacob, 2002; Roth \& Assor, 2012; Ryan \& Lynch, 1989; Vansteenkiste, Soenens, Van Petegem, \& Duriez, 2014), school contexts (Black \& Deci, 2000; Soenens \& Vansteenkiste, 2005), and romantic relationships (e.g., Knee et al., 2005; Patrick, Knee, Canevello, \& Lonsbary, 2007).

An extensive body of research suggests that conveying autonomy support is broadly preferable to control. But while there is a general assumption that speech is used to communicate motivation (Hodgins, Weibust, Weinstein, Shiffman, Miller, Coombs, \& Adair, 2010; Weinstein, 2014), little work has sought to understand how motivation is communicated. Where manipulations in experimental paradigms have involved communicating to participants, researchers have used written text to create controlling or autonomy-supportive climates (e.g., Brown, \& Carver, 2007; Hodgins, Brown, \& Carver, 2007; Levesque \& Pelletier, 2003; Radel, Sarrazin, \& Pelletier, 2009; Weinstein \& Hodgins, 2009), manipulated the way tasks are framed (e.g., Vansteenkiste et al., 2004), delivered feedback (DeMuynck et al., 2017; Ryan, 1982), or made use of spoken communications to manipulate words in motivating messages (Weinstein \& Ryan, 2010). Some studies specifically controlled for prosody by training experimenters to use the same tone across 
motivational conditions (Ryan, 1982; Grolnick \& Ryan, 1987). Although in most cases motivational communications are manipulated as part of an experimental paradigm, in some research semantic differences in naturally occurring messages are observed as part of a larger set of motivating behaviors. For example, DeMeyer and colleagues (2014) coded for teachers who "command students, use controlling language and imperatives" (p. 554) and relations with students' motivations for physical education (see similar work by Reeve \& Jang, 2006). However, no research has examined how tone of voice can be used to convey these two qualities of motivation.

\section{Social Prosody}

The current study set out to explore the role prosody plays when communicating motivational language. In the past, a variety of phenomena that can be communicated through prosody have been explored, including research on "emotional" and "social" functions (see Kreiman \& Sidtis, 2013). Here, we use "social prosody" as an umbrella term which covers speech qualities that link to psychological or social characteristics of speakers and, crucially, that do not communicate basic emotions (e.g., anger or happiness). For those latter vocal communications, the term "emotional prosody" has been applied. This research highlights that multiple acoustic parameters such as frequency, intensity, and durational cues, as well as voice quality indicators, are reliably associated with specific emotional states. While investigations vary on which physical voice attributes they report, many will describe three main attributes: pitch (i.e., as how low or high a voice is perceived), amplitude (i.e., how loud a sound is perceived), and speech rate (i.e., how fast an utterance is produced). In addition, researchers have suggested to look at the distribution of energy in different energy bands as a potential indicator for voice quality (i.e., does a voice, for example, sound harsh or breathy; c.f. Banse \& Scherer, 1996).

Still, while there is an extensive literature devoted to how emotions are conveyed or understood through prosody (see e.g., Paulmann, 2015, for cognitive/social neuroscience review), 
far less is known about how social viewpoints, beliefs, or attitudes are conveyed or understood (Mitchell \& Ross, 2013). This is surprising given how frequently, and in how wide a range of social and communicative contexts such prosody is used. Socially relevant cues that signal speakers' attitudes, opinion or personal stance often need to be inferred from prosody alone as what has been said does not necessarily need to convey the speakers' state of mind. For instance, complex constructs such as "enthusiasm", "boredom", "appreciation", or "disbelief" can be conveyed through varying voice patterns. Arguably, detecting social viewpoints, motivations, or attitudes is vital for successful communication and is similarly important to detecting emotions from voice as listeners can respond adequately by adjusting their own behavior.

Though little is known about social communicative intentions as conveyed through prosody, there is some evidence that different kinds of "social prosodic" functions including conveying humor, sarcasm, irony, or sincerity, can also be linked to specific acoustic cue configurations (e.g., Cheang \& Pell, 2008; Monetta, Cheang, Pell, 2008; Rigoulot, Fish, Pell, 2014; Scharrer, Christmann, \& Knoll, 2011), similar to findings from emotional prosody research. In addition, the power of voice has long been recognized by those who suggest that prosody can also be used to influence others (e.g., Hall, Coats, \& Smith Le Beau, 2005; Juslin \& Scherer, 2005; Ko, Sadler, Galinsky, 2015; Ko et al., 2015). These studies suggest that in spoken communication, listeners can meaningfully detect differences in temporal, pitch, and intensity measures; here we explore whether the same is true when individuals hear motivational messages.

Prosody research has primarily focused on which acoustic cues speakers use to convey meaning without the use of explicit words though some work has shown prosody plays a role in behavior change, namely operationalized by compliance with requests (e.g., Buller \& Aune, 1988; Hall, 1980; Hudson \& Blane, 1985; Smith-Genthôs, Reich, Lakin \& de Calvo, 2015). Research has yet to fully explore how well-being can be affected by prosody. Research on psychiatric disorders, 
specifically on individuals with schizophrenia that show difficulty in recognizing emotions just by listening to prosodic cues, provide the closest links so far between prosody and well-being (e.g., Blair, 2005; Bozikas, Tonia, Fokas, Karavatos, \& Kosmidis, 2006). It is, however, crucial to unravel how social prosody affects behavior in order to generalize findings to a larger context. The current investigation is a first, important step in this direction.

\section{Characterizing Motivational Prosody}

Given no research has focused on prosodic patterns characterizing control and autonomysupport, and taking into account the importance of these two distinct types of motivational styles for behavior and well-being, we initially collected auditory data aimed at characterizing motivational prosody profiles. The goal was to establish that sentences using controlling and autonomysupportive language could be defined by distinct acoustic profiles. Three common indicators were of interest: pitch, amplitude, and speech rate. In addition, voice quality (i.e. whether the voice sounds soft, rough, breathy, pressed, or similar) is sometimes included in prosodic research (e.g., Campbell \& Mokhtari, 2003). Here, we investigated the distribution of energy at different energy bands in the spectrum (c.f., Banse \& Scherer, 1996). 'Breathy' or 'narrow' voice corresponds to a higher concentration of energy in high-frequency regions and may be indicative of sternness (Guzman, Correa, Muñoz, \& Mayerhoff, 2013; Scherer, 2003), while 'lax' voices are argued to have higher proportions of low-frequency energy (Banse \& Scherer, 1996). We hypothesized that autonomy-supportive sentences can be distinguished from controlling ones in that they are spoken more softly, are less forceful across energy bands, and are spoken more slowly.

\section{Preliminary Study}

This and all future studies presented in this paper were approved by the Science and Health Faculty Ethics Sub-Committee at the University of Essex. One-hundred students recruited from the University of Rochester (USA, $n=51$ ) and the University of Essex (UK, $n=49$ ) were randomly 
assigned to an autonomy-supportive or controlling condition. The condition assignment determined the motivational content of the sentences to be read out loud. Instructions were to: “...read a number of sentences out loud... Please read them in a loud and expressive voice, and pronounce clearly. As if you really mean it." Sentences were then presented one at a time and participants read each four times to increase the likelihood of achieving a clear reading. We recruited a large sample of untrained speakers to obtain enough high quality audio data that were both authentic and recognizable. To achieve the latter goal, two independent researchers who were Master's level students and blind to the nature of the study coded collected audio files (see Banse \& Scherer, 1996 for a similar classification procedure). This initial screening determined that thirty participants spoke in a tone of voice containing audible changes in intonation, tempo, amplitude, and rhythm and which was free of stuttering, reading errors, background noise, or breathing patterns (thus, speakers sounded natural and not monotonic). These final exemplar files ( $n=30 ; 12$ males with ages 18 to 32 years, $M=22$ years; 17 UK-based) were used to analyze the effects of condition on prosody indicators.

Participants intoned a series of 12 each autonomy-supportive and controlling sentences (Deci \& Ryan, 2008; Examples: "you may do this if you choose" and "you are free to do this" (autonomy supportive) or "you have to do it my way" and "you ought to do it" (controlling)). Conditions were matched on the number of words (3 to 9 words). The final set of exemplars consisted of 720 sentences. To describe the acoustic typology of autonomy-supportive and controlling speech, pitch, intensity (mean, minimum, maximum and range) and speech rate (duration per syllable) were measured. For voice quality (Banse \& Scherer, 1996), we analyzed the proportion of energy contained in the voiced long-term average spectrum for the following bands: $0-500 \mathrm{~Hz}, 500 \mathrm{~Hz}-1 \mathrm{kHz}, 1-5 \mathrm{kHz}$, and 5-8kHz. All variables of interest were extracted using Praat (Boersma \& Weenink, 2013). The pitch range for men was set at $75-450 \mathrm{~Hz}$ and for women at 125 - 
$650 \mathrm{~Hz}$. Pitch measurements were automatically extracted using customized scripts.

Validation. A perceptual rating study confirmed that autonomy-supportive sentences were perceived to be more supportive of choice, and controlling sentences were perceived to be more pressuring. For this, an independent sample ( $n=33 ; 26$ women) of British students listened to the intoned recordings. Sentences were presented in randomized blocks grouped by condition, and the order of sentences was randomized within each block (within-subjects design). Following each sentence, participants reported the extent the sentence was 1 (not pressuring at all) to 5 (very pressuring) and 1 (does not support choice) to 5 (supports choice very much). Repeated measures ANOVAs showed that after listening to individual sentences, participants perceived controlling sentences to be more pressuring $(M=3.80)$ than autonomy-supportive sentences $(M=2.16), F(1$, $32)=133.57, p<.001$, and less supportive of choice $(M=2.06$; vs. $M=3.62), F(1,32)=31.24, p<$ .001 .

Analytic strategy. Analyses were conducted with hierarchical linear modeling (HLM; Bryk \& Raudenbush, 1992; Raudenbush \& Bryk, 2002) because audio-sentences (defined at Level 1) were nested within speakers (defined at Level 2). This method recognizes the interdependence of sentences collected from the same participant as well as variation between participants and condition. After conducting unconditional models, full models predicted major prosody parameters from gender, country of origin, and condition, as well as the interactions between predictors. Level 2 variables were centered on sample means as recommended by Bryk and Raudenbush (1992); no predictors were specified at Level $1 .^{1}$

Table 1 presents the results of all analyses, including effect sizes and confidence intervals. Findings showed that controlling for gender and country, autonomy-supportive sentences were said

\footnotetext{
${ }^{1}$ Degrees of freedom for these models are based on the total number of participants (30), with each participant having 12 scores at Level 1.
} 
with a lower pitch compared to controlling sentences. In contrast, pitch range was similar across conditions. Further, as hypothesized, participants in the controlling condition spoke with a louder voice than those in the autonomy-supportive condition (whereas condition did not impact intensity range).

Looking at the distribution of energy at different bands in the spectrum indicated that autonomy-supportive sentences were expressed with less energy in all the lower frequency bands; they were expressed in a softer or less harsh way. There was no effect of condition on the energy distribution across higher frequency bands. Also, there were no significant differences in speech rate across conditions, although a non-significant trend emerged for autonomy-supportive sentences to be read out loud more slowly. Thus, the preliminary data confirmed different prosody patterns for the two motivational qualities.

\section{Present Studies}

Based on this evidence, we set out to further define acoustic profiles of controlling and autonomy-supportive motivations. To achieve this, we asked professional speakers to intone two types of materials: a) sentences that conveyed motivations through lexical-semantic content (e.g., "you have to do it my way" for the controlling condition) and b) sentences which contained no biasing motivational words (e.g., "why don’t we meet again tomorrow”). Based on preliminary findings, we expected that sentences would be spoken in prosody patterns that distinguish controlling and autonomy-supportive motivations. Using these newly created materials, in Studies 2 to 4 we tested the hypothesis that motivational prosody alone would impact listeners' well-being and relational behaviors, in line with the large body of social psychological work referred to above. In sum, we set out to define motivational tones, and to test, for the first time, the unique impacts of autonomy-supportive and controlling tones on perceptions and listener wellness. 


\section{Study 1}

Our pilot production study suggested that autonomy-supportive and controlling sentences may be expressed with different prosodic patterns. It has been argued in the emotional prosody literature that voice samples from untrained speakers are less intense (Banse \& Scherer, 1996). It is likely that untrained students enunciate less and also modulate their voice less heavily than trained speakers. Moreover, students were not asked to speak in a motivational tone of voice, but were simply instructed to read out sentences as if they really meant them. It is likely that motivational qualities were therefore less pronounced than they would be in real-life environments. Thus, in Study 1, we used more focused instructions with trained actors who know how to use their voices to express emotions, attitudes, and motivations, and who intoned a larger set of sentences.

Initially, participants intoned motivationally laden sentences, which were semantically different across the two conditions (e.g., "you have to do this" vs. "you may do this if you choose"). Given this, differences in prosody may have been due to differences in word content of each sentence. To account for this, in Study 1, participants were asked to also read out loud semantically identical sentences after being immersed in a motivational context. Presumably, if motivation is expressed in tone of voice it should even be present in semantically identical sentences that are motivationally neutral but direct others to action (for example, "clean your room" can be said in a pressuring or in a choice-promoting, supportive way).

Based on the literature on emotional prosody (e.g., Banse \& Scherer, 1996; Pell, Paulmann, Dara, Alasseri, \& Kotz, 2009), we expected that both trained and untrained speakers would express the two types of sentences with unique prosodic patterns. In addition, we expected that actors may reveal more prominent acoustic differences between the two sentence types given their experience modulating their voice efficiently (e.g., Banse \& Scherer, 1996). In line with our preliminary findings, we hypothesized that autonomy-supportive sentences would be spoken with a lower pitch, more softly, in a less forceful way, and more slowly than controlling sentences. 


\section{Method}

Participants and procedure. Fifteen native English speakers were recruited from local acting and drama schools. Of these, 12 were females, with ages between 18 and 37 years $(M=$ 21.33 years). We aimed to recruit a minimum of 10 actors, doubling norms for work in this area (e.g., Pell et al., 2009), but accepted all actors who responded to our advertisements.

Two sets of scenarios were developed to train actors on the nature of motivational qualities, one for each within-subjects motivational condition. Stories depicted in the scenarios were adapted from one or more of the vignettes in the General Causality Orientations Scale (Deci \& Ryan, 1985), a measure of autonomous and controlled orientation that describes interpersonal contexts imbued with motivational qualities. Actors were provided with both situations taken directly from this scale (e.g., "You have a school-age daughter. On parents' night the teacher tells you that your daughter is doing poorly and doesn't seem involved in the work. You...”) and motivationally laden responses (e.g., autonomy: "Talk it over with your daughter to understand further what the problem is"; Control: "Scold her and hope she does better").

Actors recorded in individual sessions. To ensure recordings sounded natural, we used the following strategies based on previous experience in recording materials for experimental studies (e.g., Paulmann \& Kotz, 2008; Paulmann \& Uskul, 2014; Paulmann et al., 2016). First, actors were presented with scenarios describing the different conditions a few days before the recording session so they can familiarize themselves with the context, and again on the day of recording. A trained researcher also described controlling and autonomy-supportive contexts without providing hints about tone of voice. Next, actors intoned sentences from one condition (order of condition was counter-balanced) in a block design. Based on assumptions made by the Velten (1968) mood induction technique and norms in emotion prosody research (e.g., Seibert \& Ellis, 1991), actors first intoned 28 motivationally laden sentences in a matching tone of voice (see Scherer, 2003 for review 
of prosody elicitation techniques). After intoning those motivationally laden sentences from one condition, actors intoned another 28 sentences, but these were free of motivationally biasing words (semantically, motivational, neutral). Actors were not explicitly made aware of this sentence context change. We expected that motivational tones used until that point would be carried forward (c.f. Wilting, Krahmer, \& Swerts, 2006) so that speakers would continue to read the neutral sentences in motivationally laden ways. Each sentence was repeated three times or until the actor was happy that the sentence was intoned properly. Before each block, actors reread and imagined themselves in scenarios specific to the upcoming condition, and they took a break between motivational conditions to reduce any effects of one condition to another.

All sentences were recorded on Audacity software using a high quality freestanding microphone. Actors were instructed to maintain similar distance from the microphone throughout the study, which was also monitored by the experimenter. The recordings were digitized at a mono, 16-bit, 44.1k Hz sampling rate and were saved as sound files (wav). Praat (Boersma \& Weenink, 2013) was used for extraction of the acoustic data.

Materials. A rating study was performed to validate these sentences. Ninety students (47 women) reported on the extent to which each statement was pressuring (1 "not pressuring at all" to 5 "very pressuring"), whereas when hearing autonomy-supportive sentences, they reported the extent to which each supported a sense of choice (1 "does not support choice" to 5 "supports choice very much”). Three sentences from each condition were excluded at this point because they were rated as less reflective of the appropriate motivational condition (for autonomy-supportive sentences: $M=3.01$ for excluded sentences vs. $M=3.90$ for sentences we retained; for controlling sentences: $M=2.79$ for excluded sentences vs. $M=3.48$ for sentences we retained), and we dropped the three neutral sentences that were described as more pressuring $(M=4.37$ for excluded sentences). A final set of 25 motivationally neutral sentences (total 750 sentences $=375[15$ 
speakers X 25 sentences] $\mathrm{X}$ two conditions) were retained as a comparison $(M=3.16)$. The final set of sentences consisted of 25 sentences for each condition, including "it is your option to continue" (autonomy supportive), "I demand you do this now" (controlling), and "let's continue cleaning this room" (neutral).

\section{Results}

Analytic strategy. As reported above, hierarchical linear models predicted mean, minimum, maximum, and range pitch and intensity, voice quality indicators, and speech rate from gender and condition. In the present study, condition was defined at Level 1 (as it was a within-subjects predictor) and gender was defined at Level 2 . There were only three men in the study, so we did not test interaction effects with gender since any results would be prone to error (Schmidt et al., 2014). We first conducted unconditional models to assess intraclass correlation (ICC); this provided an estimate of the variability within-speakers (between sentences) and between-speakers. All parameters showed sufficient variability at both levels for conducting full models.

Second, primary models predicted prosody use as a function of condition in motivationally rich sentences, those that semantically reflected autonomy-support or control. Findings for these analyses are summarized in Table 1 alongside comparable findings from the preliminary study. Crucially, we then examined how prosody was used in semantically neutral sentences when speakers were oriented toward autonomy or control. Importantly, we also conducted analyses which tested moderation of the motivational conditions (autonomy vs. control) and prosody link by the semantic conditions (motivationally rich vs. neutral). These analyses showed that semantically neutral sentences did not differ from the motivationally rich sentences in the way that prosody was conveyed in them, $t s<1.60, p s>.12$. These results meant that actors expressed motivation in similar ways for sentences that had motivationally laden terms in them and those which did not. We present the full set of results for semantically neutral sentences below. 
Pitch. Autonomy support was expressed with a higher mean pitch than a controlling tone, $b$ $=9.95, t(746)=6.19, p<.001$ (see Table 1). Pitch range did not differ across conditions, $b=-1.00$, $t(746)=-0.35, p=.73$

Intensity. Actors expressing autonomy support spoke less loudly than when expressing control, $b=-1.97, t(746)=-7.91, p<.001$. In addition, autonomy support was expressed with a smaller range of intensity, $b=-2.68, t(746)=-9.56, p<.001$.

Voice quality. Autonomy support was spoken with lower energy in bands ranging from 0$500 \mathrm{~Hz}, b=-3.10, t(746)=-9.35, p<.001,0-1000 \mathrm{~Hz}, b=-2.54, t(746)=-10.30, p<.001 ; 500-$ $1000 \mathrm{~Hz}, b=-3.30, t(746)=-9.74, p<.001$, and $1000-5000 \mathrm{~Hz}, b=-4.15, t(746)=-12.37, p<.001$. As was the case for motivationally rich sentences, analyses of autonomy support versus control also yielded less energy between $5000-8000 \mathrm{~Hz}, b=-2.75, t(746)=-9.99, p<.001$.

Speech rate. Consistent with results presented above, autonomy support was expressed more slowly than control, $b=-.02, t(746)=-5.25, p<.001$.

\section{Conclusions}

Results from actors largely supported findings obtained from untrained students in showing that autonomy-supportive sentences can be distinguished from controlling ones in that they are spoken less loudly, are less forceful across energy bands, and are spoken more slowly. In both studies pitch differentiated these conditions, although students interpreted the role of pitch differently from actors (with autonomy-supportive sentences said in a lower pitch).

\section{Study 2}

The previous investigation indicated that autonomy-supportive and controlling motivations can be conveyed in speakers' prosody, but it did not clarify whether listeners could perceive motivation in tone of voice, alone. Next, we tested whether listeners can correctly identify motivational content in the semantically identical sentences; we expected that motivational content 
could be carried in tone of voice. We further examined the extent to which each of the key indicators was linked to the perception of support and pressure. In line with SDT theory and research (e.g., Ryan \& Deci, 2000), we hypothesized that autonomy-supportive more than controlling sentences would be perceived as promoting choice and reducing pressure. This strategy helped to further validate results obtained previously, and directly tested whether motivation could be conveyed through tone of voice, alone.

\section{Method}

Participants. Fifty native English speakers were recruited (33 females, range $=20-57$ years, $M=31.48$ years). The sample size was determined based on power analyses for $d=.45$, as identified in the previous study, and aiming for power between .90 and .95 .

Materials and procedure. To test the effect of prosody without the influence of lexicalsemantics, we employed semantically neutral sentences in studies 2-4. All of these materials were taken from the pool of sentences provided by actors in Study 1. Sentences (e.g., "do well at school", which is neither autonomy-supportive nor controlling) were presented in a random order using a within-subjects design wherein every student heard autonomy-supportive and controlling sentences (total 750 sentences $=375$ [15 speakers X 25 sentences $]$ X 2 conditions). Each recording was followed by two questions. The question "how pressuring did the speaker sound?" preceded response options 1 "not pressuring at all" to 5 "very pressuring" $(M=2.85, S D=1.32$ across conditions), and “does the speaker support the listener's sense of choice?" preceded options 1 "doesn't support the choice" to 5 "supports choice very much" $(M=2.79, S D=1.30$ across conditions).

\section{Results}

Analytic strategy. Hierarchical linear models first predicted listeners' perception of choice and pressure from condition and gender. Condition was defined at Level 2, and coded 2 for the 
autonomy support condition (neutral semantics with autonomy-supportive prosody) and 1 for the controlling condition (neutral semantics with controlling prosody).

In a second set of models we explored if differences in the primary prosody cues tested in the previous studies (mean pitch, amplitude, voice energy, and speech rate) predicted perceptions of motivational content (perceived support and pressure), with all analyses controlling for gender and condition. Since analyses were conducted with neutral, directive sentences, findings reflect effects of motivational prosody isolated from semantics. Since rating was nested within sentences all predictors were defined at Level 2. We first assessed ICC and found sufficient variability at both levels for conducting full models.

Effects of condition on listeners' perceived support and pressure. Accounting for gender ${ }^{2}$, semantically neutral sentences expressed in an autonomy-rich motivational climate were perceived by listeners to be more supportive, $b=1.14, t(747)=31.76, p<.001, d=2.32$, and less pressuring, $b=-1.54, t(747)=-37.14, p<.001, d=-2.72$, than sentences expressed in a controlling motivational tone.

Effects of prosody indicators on listeners' perceived support and pressure. Accounting for gender and condition effects (see Table 2 for this and other results of these models), higher mean amplitude was linked to lower perceptions of support and more pressure, as was higher energy concentration at $0-1000 \mathrm{~Hz}$ (selected as a broad band that was representative of the entire spectrum). Sentences that were spoken more quickly were perceived to be less supportive and more pressuring, in line with findings across the production studies which revealed that controlling sentences were expressed more quickly.

\section{Conclusions}

\footnotetext{
${ }^{2}$ Male actors were perceived to be less supportive, $b=-.25, t(747)=-4.79, p<.001, d=-.35$, and more pressuring, $b=$ $.11, t(747)=2.43, p=.02, d=.18$.
} 
In this study we examined whether listeners can correctly identify motivation in semantically neutral (and identical) sentences, through listening to prosody. As expected, we found that participants perceived these sentences spoken in a controlling prosody as more pressuring and less supportive of choice. Thus, they correctly identified motivation through tone of voice alone. Moreover, differences in prosody indicators identified previously (how loudly sentences were spoken, or how quickly, or how sternly) were linked to sentences being perceived as more controlling or supportive, in line with the idea that autonomy support can be expressed through a soft, less harsh, and slower way of speaking.

\section{Study 3}

The previous study provided initial causal evidence that prosodic motivations can be correctly detected; next, we tested whether semantically neutral but prosodically motivationally laden sentences could change people's current levels of pressure and support. While both outcomes are directly relevant to motivation, participants' states reflect less proximal outcomes of hearing motivating speakers. For example, we might expect that controlling speakers would be perceived to be more pressuring, and as a result participants would feel pressured. We furthermore tested whether prosody could also shape well-being, given autonomy-supported individuals experience more happiness and self-esteem, and lower anxiety, than those who are being controlled (e.g., O'Rourke et al., 2012; Reis et al., \& Ryan, 2000; Vansteenkiste \& Ryan, 2013). We expected that listening to autonomy-supportive prosody would improve well-being. We also expected that condition would benefit well-being indirectly through its effects on support and pressure.

\section{Method}

Participants. One hundred and fourteen students (83 women) participated in this study, with ages ranging between 18 and 45 years $(M=20.14$ years $)$. The sample size was determined aiming for power between .90 and .95 . 
Materials. We selected semantically neutral materials from our larger pool of audiorecordings that were rated as sounding choice-promoting (autonomy-supportive) or highly pressuring (controlling). Specifically, we avoided sentences that were rated with a score of "3" (out of 5) or lower in our rating study. This selection procedure resulted in 43 sentences matching this criterion. Autonomy-supportive sentences were seen to be supportive of choice $(M=3.90, S D=$ $0.21)$ and low in pressure $(M=1.67, S D=0.21)$. Controlling sentences were seen to be pressuring $(M=4.55, S D=0.14)$ and low in support for choice $(M=1.47, S D=0.26)$. To distract participants from the nature of the investigation, we also included some repetitions of materials, adding up to the presentations of 54 sentences in total.

Procedure. Each participant was tested individually in a quiet room. Participants completed baseline well-being and motivation surveys and were randomly assigned to an autonomy-supportive or controlling condition before completing a second survey assessing motivation and well-being. In the lab, participants were presented with 5 blocks of 11 sentences (10 in the final block). They were asked to listen carefully to the presented sentences which were each preceded by a fixation cross presented for $200 \mathrm{msec}$ on screen and a blank screen for $250 \mathrm{msec}$. To ensure attention to stimuli, we asked participants to indicate with a button press whether any of the sentences they had heard had been repeated by the same speaker within each block.

Perceived support and pressure. Eight items adapted from the basic psychological needs scale (Chen et al., 2014) were rated on a seven-point scale from 1 "not at all" to 7 "very much" with respect to how participants felt "right now". Four items assessed support ("I feel a sense of choice and freedom”, "I feel I can express myself honestly"), and four assessed pressure ("I feel I might be forced to do something", "I feel controlled and pressured to be certain ways"), a strategy which allowed us to expand on the findings for these two types of motivational experiences in Study 3 (as ranged from .79 to .86$)$. 
Well-being. Well-being was measured twice: once before the manipulation (baseline) and a second time after the manipulation (follow-up). Four indicators reflected well-being (positive affect, negative affect, anxiety, and self-esteem), which have been studied in composite in previous research (e.g., Legate, Ryan, \& Weinstein, 2011; Weinstein \& Hodgins, 2009; Weinstein \& Ryan, 2010). These were subjected to an exploratory factor analysis. All scales loaded onto one factor (for each of two analyses, one for each time point). Negatively valenced scales were reversed and all scales were averaged; reliability for the four indicators was $\alpha=.75$ at baseline and $\alpha=.76$ at follow-up.

Affect. Participants responded to twenty items of the positive and negative affect schedule (PANAS; Watson, Clark, \& Tellegen, 1988) with respect to how they felt 'right now' using a scale ranging from 1 "very slightly or not at all" to 5 "extremely". Of these items, 10 were measures of positive affect (e.g., "interested", "excited", "strong”), and 10 measured negative affect (e.g., “distressed, "upset”, “guilty”). Reliabilities were adequate, ranging from $\alpha$ s $=.80$ to .88 across valences and time-points.

Anxiety. The 20-item state-trait anxiety inventory, state form (Spielberger, Gorsuch, Lushene, Vagg \& Jacobs, 1983) asks about symptoms of anxiety (e.g., "I feel calm" and "I feel upset") 'right now'. Participants rated items using a scale ranging from 1 "not at all" to 4 "very much so" ( $\alpha$ s = .90 to .93$)$.

Self-esteem. The ten-item Rosenberg's self-esteem scale (Rosenberg, 1965) was adopted to measure state experiences, and was paired with a scale ranging from 1 "strongly disagree" to 4 "strongly agree". Example items include "I am satisfied with myself" and "I certainly feel useless" $(\alpha s=.86$ to .87$)$.

\section{Results}

Analytic strategy. Ordinary least squares regression analyses were used to predict support 
and pressure, and well-being, from condition. We tested indirect effects using bootstrapping analyses (Hayes, 2009; Preacher \& Hayes, 2008) to examine the extent to which any links between condition and well-being existed through the more immediate impact of condition on the motivational states of support and pressure. It was not necessary to control for speakers' gender (as was done in Study 3) because all participants listened to sentences from both male and female speakers. Correlations between all constructs are presented in Table 3; Primary findings, including relations with baseline measures, are summarized in Table 4.

Perceived support and pressure. There was no effect of condition on perceived pressure at the second time-point, $\beta=-.01, t(112)=-0.10, p=.93\left(M_{\text {autonomy }}=1.50\right.$ vs. $\left.M_{\text {control }}=1.51\right)$. However, participants in the autonomy-supportive prosody condition $(M=3.83)$ reported more perceived support, $\beta=.13, t(112)=2.26, p=.02, d=.43$ than did those in the controlling prosody condition $(M=3.59)$.

Well-being. In addition, accounting for baseline levels, those who listened to the autonomysupportive sentences reported higher well-being, $\beta=.18, t(112)=3.57, p=.001, d=.67\left(M_{\text {autonomy }}\right.$ $=3.31$ vs. $M_{\text {control }}=2.92$ ). A second model including the standardized residual of autonomysupportive motivational states at follow-up regressed onto baseline showed a link between changes in perceived support and well-being, $\beta=.20, t(111)=4.05, p<.001, d=.77$, and bootstrapping analyses suggested an indirect effect between condition and well-being was present through perceived support, estimated $b=.274$, se $=.170$ with $95 \%$ CI of .055 to $.791^{3}$.

\section{Conclusions}

Results partially replicated and expanded previous findings in showing that semantically neutral sentences spoken in either an autonomy-supportive or controlling tone could influence

\footnotetext{
${ }^{3}$ Exploratory analyses examined the effects of condition on each indicator of well-being, separately, to understand whether tone would influence some indicators of well-being more than others. Results for the composite were carried by positive and negative affect ( $p s=.002$ and .003 , respectively); the main effect on anxiety alone was not in itself significant $(t=1.49, p=.14)$.
} 
listeners: Those who had listened to autonomy-supportive sentences reported experiences of support associated with autonomy, and higher well-being than did those who listened to controlling sentences. In this study, there was no effect of condition on perceived pressure. These findings support a causal role of prosody as separate from semantics and suggest that prosody alone can influence listeners' sense of well-being, in line with the literature on motivational manipulations based on words alone (e.g., Hodgins et al., 2010; Radel et al., 2009). Also, we found that condition affected well-being through its impact on perceived support.

\section{Study 4}

Studies have shown that when participants relate to a particular situation, they experience stronger emotions than when emotions are elicited outside of a particular domain (e.g., Barrett, Mesquita, \& Gendron, 2011). We thus reasoned that, perhaps, participants did not experience a sense of pressure in the previous study since sentences were not connected to a specific experience or behavior that could be felt to be pressuring of them. Thus, in a final study we tested the effects of motivational prosody on controlled (via perceived pressure) and autonomous (via perceived support) motivational states in a school context. Previous studies suggest that motivational climates created by influential figures such as teachers are important in a school setting (e.g., Chirkov \& Ryan, 2001; De Meyer et al., 2013; Soenens \& Vansteenkiste, 2005), and that important figures influence how children experience and relate to their peers (e.g., Jennings \& Greenberg, 2009). Furthermore, in this study we tested whether motivational prosody could influence interpersonal outcomes, replicating and expanding the extant literature which shows that autonomy leads people to feel closer to others and to intend to act in prosocial ways (Gagné, 2003; Weinstein et al., 2010; Weinstein \& Ryan, 2010). Similarly, we expected that listening to sentences with autonomysupportive prosody would facilitate these positive interpersonal behaviors.

\section{Method}


Participants and procedure. One-hundred and sixty Americans were recruited on Amazon's Mechanical Turk, but fifteen were removed because they responded higher than 1 (very unlikely) to an inattention item: "I have had fatal heart attacks with other students", which was embedded in the baseline survey. The remaining 145 participants included 76 women, with ages ranging between 19 and 64 years $(M=39.20$ years). This number was in line with our recruitment goals aiming for power of $.95-.99$ given the relative ease of online recruitment.

Participants were randomly allocated to one of two conditions as in previous studies: semantically neutral sentences expressed in autonomy-supportive or controlling prosody. They first completed two questionnaires assessing closeness with peers and prosocial behaviors, thinking back to their last experience at school, the other assessing state levels of perceived support and pressure using the scale from Study 3. Following this, participants read instructions to encourage immersion in the task: "This next task involves a bit of imagination... it is very important that you take the time and effort to immerse yourself in this different experience... try to imagine yourself in the role of the student, hearing these sentences in real life...". They were then asked to spend two minutes describing the sentences they heard, reflecting on their thoughts or feelings towards them; this task was designed to extend and enhance the manipulation. In preparation for this task, before logging into the survey and again at the start of the survey, participants were asked to find a quiet and private space and to turn the sound up on their computers. As an additional check, we recorded the amount of time participants spent on each manipulation page. Following the manipulation, participants once again completed surveys assessing state levels of support and pressure, as well as closeness and prosocial behavior intention, this time thinking about the hypothetical classroom in which they heard the autonomy-supportive or controlling prosody sentences.

Materials. Autonomy-supportive or controlling conditions were delivered using sentences from our larger pool of materials. Selection was based on context expressed in materials as the topic 
of the sentences had to be specific to the school domain (e.g., "Why don't you go to school now"). Sentence contexts were repeated but never spoken by the same speaker. Sentences $(n=10)$ selected for the autonomy-supportive prosody condition were rated $M=3.74(S D=0.41)$ on a five-point scale assessing perceived choice and $M=1.64(S D=0.33)$ on a five-point scale assessing perceived pressure. Sentences $(n=10)$ selected for the controlling prosody condition were rated $M$ $=1.58(S D=0.30)$ for choice and $M=4.36(S D=0.27)$ for pressure.

Closeness and prosocial behavior. Participants responded to nine items using a scale ranging from 1 "very unlikely" to 7 "very likely". At baseline, they were asked to "think back to when you were at school last; how likely were you to...", and at follow-up they were given the instructions "Please think of yourself in the school where you might hear the sentences which were just spoken; how likely were you to...". They then responded to five items assessing closeness taken from the Intrinsic Motivation Inventory (IMI; Ryan, Mims, \& Koestner, 1983; with further validation in McAuley, Duncan, \& Tammen, 1987), including "feel like you could really trust the other students", and "feel close to the other students" ( $\alpha$ s = .77 and .93 for baseline and follow-up, respectively). They also responded to four items assessing prosocial behavior in the classroom (items were: "help another student study for an exam"; "help another student with his homework"; "assist another student in carrying a pile of heavy books"; "offer some of your lunch after another student forgot hers"; $\alpha=.78$ and $\alpha=.93$ for the two time points).

\section{Results}

Analytic Strategy. Ordinary least squares regression analyses were used to predict perceived support and pressure, as well as interpersonal outcomes from condition, and we tested indirect effects as in Study 3. Similar to Study 3, we did not control for speakers' gender because all participants listened to sentences from both male and female speakers. Correlations between constructs are presented in Table 3. Primary findings, including relations with baseline measures, 
are summarized in Table 4. See Figure 1 for the full model.

Perceived support and pressure. Participants who listened to autonomy-supportive prosody sentences reported higher state levels of feeling supported, $\beta=.36, t(142)=5.21, p<.001$, $d=.87\left(M_{\text {autonomy }}=4.69\right.$ vs. $\left.M_{\text {control }}=4.09\right)$, accounting for their reports at baseline. As well, the autonomy-supportive prosody condition was linked to lower feelings of pressure at this time, $\beta=$ $.48, t(142)=-7.35, p<.001, d=1.23\left(M_{\text {autonomy }}=2.29\right.$ vs. $\left.M_{\text {control }}=4.02\right)$.

Interpersonal outcomes. In scenarios where autonomy-supportive prosody motivation was used, participants anticipated feeling more closeness to students, $\beta=.46, t(142)=7.19, p<.001, d$ $=1.21\left(M_{\text {autonomy }}=5.13\right.$ vs. $\left.M_{\text {control }}=3.69\right)$. Moreover, those in hypothetical autonomy-supportive classrooms were also more likely to anticipate helping other students, $\beta=.45, \mathrm{t}(142)=6.31, \mathrm{p}<$ $.001, d=1.06\left(M_{\text {autonomy }}=5.69\right.$ vs. $\left.M_{\text {control }}=4.37\right)$.

Discrepancy between previous school experiences (measured at baseline) and perceptions of the hypothetical school (measured at follow-up) served as the mediator between condition and interpersonal outcomes. Differences in levels of both perceived support, $\beta=.20, t(141)=3.04, p=$ $.004, d=.51$, and pressure, $\beta=-.22, t(141)=-3.01, p=.002, d=.51$, were linked to feelings of closeness with other students, and they were both linked to prosocial behavior (support: $\beta=.20$, $t(141)=2.71, p=.008, d=.46$, pressure: $\beta=-.31, t(141)=-3.87, p<.001, d=.65$; see Figure 1$)$. Bootstrapping analyses suggested an indirect effect was present through feeling supported for closeness, estimated $b=.191, s e=.094$ with $95 \%$ CI of .041 to .409 , and prosocial behavior, estimated $b=.179$, se $=.101$ with $95 \%$ CI of .041 to .441 . Moreover, an indirect effect was present through feeling pressured for both predictors, estimated $b=.470, s e=.160$ with $95 \%$ CI of .180 to .810 , and, estimated $b=.179$, se $=.093$ with $95 \%$ CI of .031 to .410 .

\section{Conclusions}

Study 4 tested the effects of motivational prosody in a hypothetical school context, given 
motivation is often studied in the context of education (e.g., Black \& Deci, 2000; Chirkov \& Ryan, 2001; Reeve, 2006). Thus, here, participants were given an interpretative lens within which to understand messages. The results replicated those of Studies 2 and 3 in that participants who listened to neutral sentences intoned in an autonomy-supportive tone of voice reported more support and less pressure. Moreover, we tested the role of motivational prosody in shaping interpersonal outcomes linked to autonomy-supportive climates (e.g., Weinstein et al., 2010). Participants who listened to neutral sentences intoned in autonomy-supportive tone of voice felt closer to their hypothetical peers and were more likely to intend to help them than those in the controlling prosody condition.

\section{Discussion}

The present studies defined the impact of motivational prosody. In doing so, we identified patterns of prosody characterizing two types of motivating speech, autonomy-supportive and controlling, that differentially impact well-being and behavior (Ryan \& Deci, 2000). We also saw that motivational prosody alone can shape personal and interpersonal experiences in much the same way that words do.

We first defined patterns of motivational prosody that characterize how autonomysupportive speech (which feels supportive of choice and self-expression) sounds in comparison to controlling, pressuring speech. Importantly, when asking professional speakers to intone materials, differences between autonomy-supportive and controlling styles of speaking were carried through when speakers intoned motivationally neutral sentences (e.g., "clean your room!"). It seems these motivationally ambiguous sentences can be expressed (and perceived) with an autonomy-supportive or controlling tone. The next study found that listeners could identify motivational qualities by prosody alone, and that they perceived key prosodic characteristics - louder voice, harsher sound, and slower speaking rate, to be more pressuring and less supportive of choice. 


\section{Acoustic Characteristics of Motivational Speech}

One of the most frequently explored psycho-acoustic parameters in prosody research is pitch. Pitch modulation alone has the ability to change the meaning of a sentence (compare 'she is really mad?' vs. 'she is really mad!'). Interestingly, the two production investigations revealed conflicting findings for this parameter as autonomy-supportive messages such as "you're free to do this" were spoken with a lower pitch in the preliminary investigation, while actors interpreted this motivational context with a higher pitch. Different pitch directions have been linked to vocally expressed attitudes (e.g., boredom can be expressed with lower F0 than neutral speech, or with no change in F0) and emotions (e.g., vocal expressions of disgust and fear have reported mixed F0 results; Kreiman \& Sidtis, 2013, Scherer \& Banse, 1996), suggesting that variation of some acoustic parameters depends on speaker context and interpretation. Perhaps, here, untrained and relatively unguided students were less confident or self-assured, pointing to future research which examines pitch using recordings from motivators in vertical relationship, who may be more assertive or selfassured (e.g., parents and teachers) and horizontal relationships, who may hesitate when motivating (e.g., friends), and from relatively powerful, confident motivators (e.g., bosses, political leaders) and those who are relatively powerless (e.g., when asking a favor). Interestingly, pitch was the one key indicator in Study 2 which did not explain independent variance in perceptions of motivational content. These findings across three studies indicated that speakers can modulate pitch differently when expressing different motivational states and listeners will still be able to recognize the motivation conveyed. In contrast to written words, the speech signal is dynamic in nature and pitch changes can manifest at different time points, be smooth or abrupt, and be defined with an upward or downward inflection. We speculate that the more nuanced characteristics of pitch, for example where it falls and rises in a sentence (i.e. pitch contour), may more accurately differentiate motivational styles. 
Across two studies, controlling sentences were expressed more loudly; the energy used to produce controlling sentences was higher than when producing autonomy-supportive messages. Arguably, controlling speech requires 'effort' given that one is attempting to directly manipulate someone else's behavior (Deci \& Ryan, 1987). In fact, controlling speech was also characterized by a slower speech rate, suggesting that speakers try to emphasize the message. It is well known that physiological modifications of the systems involved in speech production (i.e. respiratory, phonatory, articulatory) systematically alter a speaker's voice, and research in SDT has linked control motivation to physiological stress (Weinstein \& Ryan, 2012). Physiological arousal experienced when attempting to be controlling may also explain some of the variance in modifications of voice parameters observed here.

As mentioned previously, voice quality (e.g., rough, harsh, or whispery voice) features are less explored in the literature, but have been linked to the amount of energy present within certain frequency bands (Banse \& Scherer, 1996). Specifically, in past research a 'breathy' voice corresponds to a higher concentration of energy in high-frequency regions (Guzman et al., 2013), while a 'narrow' voice is argued to contain more high frequency energy indicative of sternness (Scherer, 2003). Consequently, 'lax' voices have higher proportions of low-frequency energy (Banse \& Scherer, 1996). In two studies, analyses covering both low (up to1000 Hz) and high (up to $8000 \mathrm{~Hz}$ ) frequencies revealed that energy distribution was higher for controlling sentences on all frequencies up to $5 \mathrm{kHz}$. Actors, those who have more control over their vocal apparatus, also showed increased energy for controlling sentences in the highest frequencies $(5-8 \mathrm{kHz})$. Together, this suggests that controlling sentences are produced with a less breathy or stern sounding voice quality. In fact, accounts on how internal states exemplify through acoustic parameters (e.g., Scherer, 2003) predict that powerful voices carry strong energy across the entire frequency range; the current data nicely fit with this hypothesis. Together, they suggest that controlling sentences are 
produced with a stern sounding voice, and indeed sternness, loudness, and slow speech were key features of sentences perceived in Study 2 to be controlling.

\section{Well-Being Outcomes of Motivational Prosody}

In two further studies we explored whether motivational prosody can shape listeners' experiences in a way consistent with the effects of motivating words. In Study 2, sentences said in an autonomy-supportive (versus controlling) tone of voice resulted in increased well-being. These findings inform and expand the already well-developed literature which has demonstrated robust links between being motivation and indicators of well-being (e.g., Deci, La Guardia, Moller, Scheiner, \& Ryan, 2006; Patrick et al., 2007; Reis et al., 2000; Ryan \& Deci, 2000). They suggest that well-being is shaped not only by the words used to communicate motivational sentences, but also by the tone of voice. Research has shown that among others, romantic partners (Patrick et al., 2007), friends (Deci et al., 2006), parents (Soenens \& Vansteenkiste, 2005), and bosses (Thompson $\&$ Prottas, 2006) can increase the well-being of others through being more autonomy-supportive. The present work suggests that these individuals can influence well-being merely by using a different tone of voice.

\section{Prosody Effects on Relationships}

Our final study demonstrated the power of motivational prosody in affecting relationships. Imagining hypothetical classrooms in which autonomy-supportive prosody was used resulted in feelings of closeness and a greater intention to help peers through a variety of prosocial actions. These findings are in line with work pointing to these interpersonal benefits after autonomysupportive motivational contexts are elicited through words alone (typically though not exclusively through written text; Gagné, 2003; Niemiec, 2010; Weinstein, Hodgins, \& Ryan, 2010; Weinstein \& Ryan, 2010), and in real-life relationships, for example with adolescent peers (Soenens, Vansteenkiste, Goossens, Duriez, \& Niemiec, 2008) and in schools (Deci, Vallerand, Pelletier, \& 
Ryan, 1991). Interestingly, although our school context can be considered artificial, results showed that listening to controlling prosody increased pressure in participants. It will be important to test the effects of motivational prosody in more varied laboratory settings using more interactive scenarios (e.g., participating in computer games).

Although our studies focused on subjective experiences, some SDT literature has been interested in behavioral indicators of sustained attention and long-term behavioral engagement (e.g., Black \& Deci, 2000; Gagné, 2003; Vansteenkiste, Simons, Lens, Sheldon, \& Deci, 2004). It would be fascinating to explore whether prosody embedded in instructions would promote differential responding on these outcomes, for example using free-choice period paradigms (e.g., Deci, 1971; Deci, Driver, Hotchkiss, Robbins, \& Wilson, 1993; Hagger, Koch, \& Chatzisarantis, 2015) and examining students' and athletes' behaviors (e.g., performance, engagement) as a function of teacher or coach prosody.

\section{Findings within a Broad Literature in Motivation}

In Studies 3 and 4 changes in key outcomes took place indirectly through the effects of condition on the motivationally relevant experiences of perceived pressure (an outcome of controlling contexts; Study 4 only) and support (an outcome of autonomy-enhancing contexts; both studies; Deci \& Ryan, 1987). Though effects were consistent for perceived support, the non-specific nature of the Study 3 manipulation, wherein sentences were heard out of context, was not sufficient for inducing pressure; in line with research showing people experience emotional primes more strongly when they can relate to emotion relevant situations (Barrett et al., 2011). Along with these proximal consequences of motivational communications, others might be tested in future research. For example, we did not test relatedness to speakers or defensive responses to communications as potential mediators which might help explain the effects identified in Studies 3 and 4, but there is reason to believe that people feel closer and less defensive/threatened when speakers use more 
supportive versus controlling tones of voice, based on previous research linking these outcomes to motivational climates more broadly (e.g., Cheon, Reeve, \& Moon, 2002; Hodgins et al., 2010; Ryan \& Powelson, 1999).

Our findings supported the view that perceptually distinct vocal profiles are used to express motivational speech and by doing so inform both the motivational literature and the attitudinal prosody literature. Results suggested that motivators can influence others through tone of voice as well as through words. In fact, motivators who are self-conscious or deceptive (e.g., politicians) may use autonomy-supportive words paired with a controlling tone to subtly manipulate behavior. In addition, motivational communications influence can also affect bystanders in unintended ways (children overhearing a conversation between their parents; spouses of medical patients who receive motivating treatment advice). These ubiquitous communications comprise of both words and prosody, and at times only prosody may carry to influence listeners. Finally, findings inform motivational research in SDT that manipulates motivation - the very manipulations used in the field can be modified and constructed systematically to reproduce expressive tones of voice.

These results viewed in light of emotional prosody work also inform the link between emotions and motivation. Although basic emotions and motivational styles may correlate, for example, someone who is angry may use a controlling tone, the two constructs are conceptually and operationally distinct - someone who is angry may still use autonomy-supportive language. Accordingly, emotions and motivation may be expected to show related but distinct prosody patterns, so that understanding basic emotions does not translate to defining motivational prosody patterns. Here, we add to a growing body of evidence which suggests that different social signals (i.e. attitudes, internal states, motivations) are communicated with distinct prosodic profiles (e.g., Ranganath, Jurafsky, McFarland, 2013; Ko et al., 2014). Specifically, we demonstrate that controlling sentences were expressed with high intensity and faster speaking rate, and was 
interpreted differently in terms of pitch across students and actors. In contrast, autonomy-supportive messages were expressed with varying pitch patterns from students (lower pitch) and actors (higher pitch), as well as with a decrease in volume and an increase in speech rate. Interestingly, joyful messages are usually intoned by increasing all of these measurements (c.f., Banse \& Scherer, 1996). Thus, the current data provide evidence that motivations can be expressed with distinct acoustic patterns which are not a simple mirroring of previously reported patterns for emotions or other social vocal signals. Given the recent interest in linking specific emotions to certain motivations (Vandercammen, Hofmans, \& Theuns, 2014), future studies should explore how motivations are expressed when the speaker feels either positive (e.g., joyful, happy) or negative (e.g., angry, sad, frightened).

\section{Final Thoughts}

It is worth noting that listeners were generally young and sentences were presented in a tightly controlled lab setting. Findings should be replicated with older participants and those in reallife interactions. Indeed, when participants in these studies imagined themselves in a school setting the effects of prosody on perceived pressure appeared to be more robust. The most powerful studies would record prosody in real-life situations, for example between parents and children, teachers and students, or doctors and patients, and explore its role in these situations. Furthermore, in Studies 3 and 4, listeners' experiences were assessed with self-reported measures and further studies could evaluate the effects of prosody using physiological measurements (Weinstein \& Ryan, 2010), behavioral measures such as actual prosocial giving, or observational measures such as videotaped interpersonal behaviors (Knee et al., 2005), or assessments of task persistence (Deci \& Ryan, 1987; Pelletier, Fortier, Vallerand, \& Briere, 2001). A third potential limitation of studies 2-4 was that they used materials produced during our professional actor recording sessions. Future research should replicate and extend the present set of studies using even more varied stimuli (i.e., use 
different speakers and more varying sentence contents). Moreover, the current studies compared autonomy-supportive tones to controlling tones, without including a neutral comparison. Yet recent theorizing and literature has indicated that autonomy can be actively supported (perhaps with autonomy-supportive tones) or actively thwarted (perhaps through controlling tones; Vansteenkiste \& Ryan, 2013); future studies should include a neutral comparison to contrast against each quality of tone, and might use these to differentially predict both ill-being and well-being, given that a controlling tone might be expected to relate more closely to ill-being, while an autonomysupportive tone might foster well-being (Chen et al., 2015). Similarly, here we focused on wellbeing broadly, and additional work might differentiate forms of wellness which are hedonic, or pleasure-focused (for example, affect), and eudaimonic - reflective of actualizing one's potential (for example, energy; meaning; Ryan \& Deci, 2001).

The current research was aimed at classifying motivational prosody patterns to develop an acoustic typology for autonomy-supportive and controlling motivations and to explore how these acoustic patterns can influence listeners' experiences; ultimately, our goal was to advance a richer understanding of the nature of motivational communication. This is important for a number of reasons. First, prosody research has yet to be generalized to the large body of motivational research and can inform motivational interventions in experimental and applied settings. Furthermore, these motivational communications are relevant in political communications, parent-child relationships, sports and exercise, education, the workplace, and healthcare (see review in Weinstein, 2014), and as such this fundamental work on motivational communications can be extended across the gamut of human interactions. Finally, speech inconsistencies and deceptive motivational influences can be studied for the first time once tone of voice is understood and defined as independent from words. 


\section{References}

Banse R., \& Scherer, K. R. (1996). Acoustic profiles in vocal emotion expression. Journal of Personality and Social Psychology, 70, 3, 614-636.

Barber, B. K. (1996). Parental psychological control: Revisiting a neglected construct. Child Development, 67, 3296-3319.

Barrett, L. F., Mesquita, B., \& Gendron, M. (2011). Context in emotion perception. Current Directions in Psychological Science, 20(5), 286-290.

Batliner, A., Steidl, S., Schuller, B., Seppi, D., Vogt, T., Devillers, L., Vidrascu, L., Amir, N., Kessous, L., \& Aharonson, V. (2007). The impact of F0 extraction errors on the classification of prominence and emotion. Proceedings of the $16^{\text {th }}$ International Congress of Phonetic Sciences, ICPhS.

Black, A. E., \& Deci, E. L. (2000). The effects of instructors' autonomy support and students' autonomous motivation on learning organic chemistry: A self-determination theory perspective. Science Education, 84(6), 740-756.

Blair, R. J. R. (2005). Responding to the emotions of others: dissociating forms of empathy through the study of typical and psychiatric populations.Consciousness and cognition, 14(4), 698718.

Boersma, P., \& Weenink, D. (2013). Praat: Doing phonetics by computer (Computer program), Version 4.3. 14. Available at: http://www. praat.org.

Borkowska, B., \& Pawlowski, B. (2011). Female voice frequency in the context of dominance and attractiveness perception. Animal Behaviour, 82(1), 55-59.

Bozikas, V. P., Tonia, T., Fokas, K., Karavatos, A., \& Kosmidis, M. H. (2006). Impaired emotion processing in remitted patients with bipolar disorder. Journal of affective disorders, 91(1), 53-56. 
Bryk, A. S., \& Raudenbush, S. W. (1992). Hierarchical linear models: Applications and data analysis methods (1st Edition). Newbury Park, CA: Sage Publications.

Bryant, G. A., \& Fox Tree, J. E. (2002). Recognizing verbal irony in spontaneous speech. Metaphor and symbol, 17(2), 99-119.

Bugental, D.B., Henker, B, \& Whalen, C.K. (1976). Attributional antecedents of verbal and vocal assertiveness. Journal of Personality and Social Psychology, 34, 405-411.

Bugental, D.B., \& Love, L. (1975). Nonassertive expression of parental approval and disapproval and its relationship to child disturbance. Child Development, 46, 747-752.

Buller, D.B., \& Aune, R.K. (1988). The effects of vocalics and nonverbal sensitivity on compliance a speech accommodation theory explanation. Human Communication Research, 14, 301332.

Bureau, J., \& Mageau, G. A. (2014). Parental autonomy support and honesty: The mediating role of identification with the honesty value and perceived costs and benefits of honesty. Journal of Adolescence, 37, 225-236.

Campbell, N. \& Mokhtari, P. (2003). Voice quality: the $4^{\text {th }}$ prosodic dimension. Proceedings of the $15^{\text {th }}$ International Congress of Phonetic Sciences.

Cheang, H. S., \& Pell, M. D. (2008). The sound of sarcasm. Speech Communication, 50, 366-381.

Chen, B., Vansteenkiste, M., Beyers, W., Boone, L., Deci, E. L., Van der Kaap-Deeder, J., ... \& Verstuyf, J. (2014). Basic psychological need satisfaction, need frustration, and need strength across four cultures. Motivation and Emotion, 1-21.

Cheon, S. H., Reeve, J., \& Moon, I. S. (2012). Experimentally based, longitudinally designed, teacher-focused intervention to help physical education teachers be more autonomy supportive toward their students. Journal of Sport and Exercise Psychology, 34(3), 365-396. 
Chirkov, V. I., \& Ryan, R. M. (2001). Parent and teacher autonomy support in Russian and US adolescents common effects on well-being and academic motivation. Journal of Crosscultural Psychology, 32(5), 618-635.

Cummings, G. (2014). The new statistics: Why and how. Psychological Science, 25, 1, 7-29.

De Meyer, J., Borghouts, L., Tallir, I., Soenens, B., Vansteenkiste, M., Speleers, L., Aelterman, N., Van den Berghe, L., Haerens, L., \& Cardon, G. (2013). Relation between observed controlling teaching behavior and students' motivation in physical education. Journal of Educational Psychology, 106, 541-554.

Deci, E. L. (1971). Effects of externally mediated rewards on intrinsic motivation. Journal of Personality and Social Psychology, 18, 105-115.

Deci, E. L., Driver, R. E., Hotchkiss, L., Robbins, R. J., \& Wilson, I. M. (1993). The Relation of Mothers Controlling Vocalizations to Child- ren s Intrinsic Motivation. Journal of Experimental Child Psychology, 55, 151-162.

Deci, E. L., La Guardia, J. G., Moller, A. C., Scheiner, M. J., \& Ryan, R. M. (2006). On the benefits of giving as well as receiving autonomy support: Mutuality in close friendships. Personality and Social Psychology Bulletin, 32(3), 313-327.

Deci, E. L., \& Ryan, R. M. (1985). The general causality orientations scale: Self-determination in personality. Journal of research in personality, 19(2), 109-134.

Deci, E. L., \& Ryan, R. M. (1987). The support of autonomy and the control of behavior. Journal of personality and social psychology, 53(6), 1024.

Deci, E. L., \& Ryan, R. M. (2008). Self-determination theory: A macrotheory of human motivation, development, and health. Canadian Psychology/Psychologie canadienne, 49(3), 182.

Deci, E. L., Vallerand, R. J., Pelletier, L. G., \& Ryan, R. M. (1991). Motivation and education: The self-determination perspective. Educational psychologist, 26(3-4), 325-346. 
De Meyer, J., Tallir, I. B., Soenens, B., Vansteenkiste, M., Aelterman, N., Van den Berghe, L., ... \& Haerens, L. (2014). Does observed controlling teaching behavior relate to students' motivation in physical education?. Journal of Educational Psychology, 106(2), 541.

De Muynck, G. J., Vansteenkiste, M., Delrue, J., Aelterman, N., Haerens, L., \& Soenens, B. (2017). The Effects of Feedback Valence and Style on Need Satisfaction, Self-Talk, and Perseverance among Tennis Players: An Experimental Study. Journal of Sport and Exercise Psychology, 1-38.

Flink, C., Boggiano, A. K., \& Barrett, M. (1990). Controlling teaching strategies: Undermining children's self-determination and performance. Journal of Personality and Social Psychology, 26, 5-23.

Gagné, M. (2003). The role of autonomy support and autonomy orientation in prosocial behavior engagement. Motivation and Emotion, 27, 199-223.

Gagné, M. (2003b). Autonomy support and need satisfaction in the motivation and well-being of gymnasts. Journal of Applied Sport Psychology, 15(4), 372-390.

Gecas, V., \& Schwalbe, M. L. (1986). Parental behavior and adolescent self-esteem. Journal of Marriage and the Family, 37-46.

Grolnick, W. S., Gurland, S. T., DeCourcey, W., \& Jacob, K. (2002). Antecedents and consequences of mothers' autonomy support: an experimental investigation. Developmental Psychology, 38(1), 143.

Guzman, M., Correa, S., Muñoz, D., \& Mayerhoff, R. (2013). Influence of spectral energy distribution of emotional expression. Journal of Voice, 27(1), 129-139.

Hagger, M. S., Koch, S., \& Chatzisarantis, N. L. (2015). The effect of causality orientations and positive competence-enhancing feedback on intrinsic motivation: A test of additive and interactive effects. Personality and Individual Differences, 72, 107-111. 
Hall, J. A. (1980). Voice tone and persuasion. Journal of Personality and Social Psychology, 38(6), 924-934.

Hall, J. A., Coats, E. J., \& Smith LeBeau, L. (2005). Nonverbal behavior and the vertical dimension of social relations: A meta-analysis. Psychological Bulletin, 131, 6, 898-924.

Hayes, A. F. (2009). Beyond Baron and Kenny: Statistical mediation analysis in the new millennium. Communication Monographs, 76(4), 408-420.

Hodgins, H. S., Brown, A. B., \& Carver, B. (2007). Autonomy and control motivation and selfesteem. Self and Identity, 6(2-3), 189-208.

Hodgins, H. S., Weibust, K. S., Weinstein, N., Shiffman, S., Miller, A., Coombs, G., \& Adair, K. C. (2010). The cost of self-protection: Threat response and performance as a function of autonomy-supportive and controlled motivations. Personality and Social Psychology Bulletin, 36(8), 1101-1114.

Hudson, A., \& Blane, M. The importance of non verbal behavior in giving instructions to children. Child \& Family Behavior Therapy, 7(2), 1-10.

Jennings, P. A., \& Greenberg, M. T. (2009). The prosocial classroom: Teacher social and emotional competence in relation to student and classroom outcomes. Review of educational research, 79(1), 491-525.

Jõesaar, H., Hein, V., \& Hagger, M. S. (2011). Peer influence on young athletes' need satisfaction, intrinsic motivation and persistence in sport: A 12-month prospective study. Psychology of Sport and Exercise, 2, 500-508.

Juslin, P. N., Scherer, K. R., (2005). Vocal expression of affect. In: J. A. Harrigan, R. Rosenthal \& K. R. Scherer (eds) The new handbook of methods in nonverbal behavior research, Oxford, Oxford University Press. 
Knee, C. R., Lonsbary, C., Canevello, A., \& Patrick, H. (2005). Self-determination and conflict in romantic relationships. Journal of personality and social psychology, 89(6), 997.

Knee, C. R., Hadden, B. W., Porter, B., \& Rodriguez, L. M. (2013). Self-determination theory and romantic relationship processes. Personality and Social Psychology Review, 17 (4), 307324.

Ko, S. J., Sadler, M. S., \& Galinsky, A. D. (2014). The Sound of Power Conveying and Detecting Hierarchical Rank Through Voice. Psychological Science, 0956797614553009.

Kreiman, J., \& Sidtis, D. (2013). Foundations of voice studies. An interdisciplinary approach to voice production and perception. Blackwell Publishing, Ltd. Oxford, UK.

Legate, N., Ryan, R. M. \& Weinstein, N. (2011). Is coming out always a "good thing"? Exploring the relations of autonomy support, outness, and wellness for lesbian, gay, and bisexual individuals. Social Psychological and Personality Science. Advance online publication. doi $10.1177 / 1948550611411929$

Levesque, C., \& Pelletier, L. G. (2003). On the investigation of primed and chronic autonomous and heteronomous motivational orientations. Personality and Social Psychology Bulletin, 29(12), 1570-1584.

McAuley, E., Duncan, T., \& Tammen, V. V. (1987). Psychometric properties of the Intrinsic Motivation Inventory in a competitive sport setting: A confirmatory factor analysis. Research Quarterly for Exercise and Sport, 60, 48-58.

Mitchell, R. L., \& Ross, E. D. (2013). Attitudinal prosody: What we know and directions for future study. Neuroscience \& Biobehavioral Reviews, 37(3), 471-479.

Monetta, L., Cheang, H.S., Pell, M.D. (2008). Understanding speaker attitudes from prosody by adults with Parkinson's disease. Journal of Neuropsychology, 2, 415-430. 
Niemiec, C. P. (2010). Contextual supports for autonomy and the development of high-quality relationships following mutual self-disclosure (Doctoral dissertation, University of Rochester).

Nygaard, L. C., \& Lunders, E. R. (2002). Resolution of lexical ambiguity by emotional tone of voice. Memory \& Cognition, 30(4), 583-593.

O'Rourke, D. J., Smith, R. E., Smoll, F. L., \& Cumming, S. P. (2012). Parent-Initiated Motivational Climate, Self-Esteem, and Autonomous Motivation in Young Athletes: Testing Propositions from Achievement Goal and Self-Determination Theories. Child Development Research, $2012,393914$.

Patrick, H., Knee, C. R., Canevello, A., \& Lonsbary, C. (2007). The role of need fulfillment in relationship functioning and well-being: a self-determination theory perspective. Journal of personality and social psychology, 92(3), 434.

Paulmann, S. (2015). The Neurocognition of Prosody. In G. Hickok and S. Small (Eds.), Neurobiology of Language. San Diego: Elsevier.

Pell, M. D., Paulmann, S., Dara, C., Alasseri, A., \& Kotz, S. A. (2009). Factors in the recognition of vocally expressed emotions: a comparison of four languages. Journal of Phonetics, 37, 417435.

Pelletier, L. G., Fortier, M. S., Vallerand, R. J., \& Briere, N. M. (2001). Associations among perceived autonomy support, forms of self-regulation, and persistence: A prospective study. Motivation and Emotion, 25(4), 279-306.

Preacher, K. J., \& Hayes, A. F. (2008). Asymptotic and resampling strategies for assessing and comparing indirect effects in multiple mediator models. Behavior research methods, 40(3), 879-891. 
Radel, R., Sarrazin, P., \& Pelletier, L. G. (2009). Evidence of subliminally primed motivational orientations: The effects of unconscious motivational processes on the performance of a new motor task. Journal of Sport and Exercise Psychology, 31, 651-674.

Ranganath, R., Jurafsky, D., \& McFarland, D. A. (2013). Detecting friendly, flirtatious, awkward, and assertive speech in speed-dates. Computer Speech \& Language, 27(1), 89-115.

Raudenbush, S. W., \& Bryk, A. S. (2002). Hierarchical linear models ( $2^{\text {nd }}$ Edition). Thousand Oaks: Sage Publications.

Reeve, J. (2006). Teachers as facilitators: What autonomy- supportive teachers do and why their students benefit. The Elementary School Journal, 106(3), 225-236.

Reeve, J. (2009). Why teachers adopt a controlling motivating style toward students and how they can become more autonomy supportive. Educational Psychologist, 44(3), 159-175.

Reeve, J., \& Jang, H. (2006). What teachers say and do to support students' autonomy during a learning activity. Journal of educational psychology, 98(1), 209.

Reeve, J., Jang, H., Carrell, D., Jeon, S., \& Barch, J. (2004). Enhancing students' engagement by increasing teachers' autonomy support. Motivation and emotion, 28(2), 147-169.

Reeve, J., Jang, H., Hardre, P., \& Omura, M. (2002). Providing a rationale in an autonomysupportive way as a strategy to motivate others during an uninteresting activity. Motivation and emotion, 26(3), 183-207.

Reis, H. T., Sheldon, K. M., Gable, S. L., Roscoe, J., \& Ryan, R. M. (2000). Daily well-being: The role of autonomy, competence, and relatedness. Personality and social psychology bulletin, $26(4), 419-435$.

Rigoulot, S., Fish, K., \& Pell, M. D. (2014). Neural correlates of inferring speaker sincerity from white lies: An event-related potential source localization study. Brain research, 1565, 48-62. 
Rosenberg, M. (1965). Society and the adolescent self-image. Princeton, NJ: Princeton University Press.

Roth, G., \& Assor, A. (2012). The cost of parental pressure to express emotions: Conditional regard and autonomy support as predictors of emotion regulation and intimacy. Journal of Adolescence, 35, 799-808.

Roth, G., Assor, A., Niemiec, C. P., Ryan, R. M., \& Deci, E. L. (2009). The emotional and academic consequences of parental conditional regard: comparing conditional positive regard, conditional negative regard, and autonomy support as parenting practices. Developmental psychology, 45(4), 1119.

Ryan, R. M. (1982). Control and information in the intrapersonal sphere: An extension of cognitive evaluation theory. Journal of personality and social psychology, 43(3), 450.

Ryan, R. M. (Ed.). (2012). The Oxford handbook of human motivation. Oxford University Press.

Ryan, R. M., \& Deci, E. L. (2000). Self-determination theory and the facilitation of intrinsic motivation, social development, and well-being. American psychologist, 55(1), 68.

Ryan, R. M., \& Deci, E. L. (2001). On happiness and human potentials: A review of research on hedonic and eudaimonic well-being. Annual review of psychology, 52(1), 141-166.

Ryan, R. M., \& Frederick, C. (1997). On energy, personality, and health: Subjective vitality as a dynamic reflection of well-being. Journal of personality, 65(3), 529-565.

Ryan, R. M., \& Lynch, J. H. (1989). Emotional autonomy versus detachment: Revisiting the vicissitudes of adolescence and young adulthood. Child development, 340-356.

Ryan, R. M., Mims, V., \& Koestner, R. (1983). Relation of reward contingency and interpersonal context to intrinsic motivation: A review and test using cognitive evaluation theory. Journal of Personality and Social Psychology, 45, 736-750. 
Ryan, R. M., \& Powelson, C. L. (1991). Autonomy and relatedness as fundamental to motivation and education. The journal of experimental education, 60(1), 49-66.

Savard, A., Joussemet, M., Pelletier, L. G., \& Mageau, G. A. (2013). The benefits of autonomy support for adolescents with severe emotional and behavioral problems. Motivation and Emotion, 37, 688-700.

Scharrer, L., Christmann, U., \& Knoll, M. (2011). Voice Modulations in German Ironic Speech. Language and Speech, 54, 435-465.

Scherer, K. (2003). Vocal communication of emotion: A review of research paradigms. Speech Communication, 40, 227-256.

Schmidt, A. F., Groenwold, R. H. H., Knol, M. J., Hoes, A. W., Nielen, M., Roes, K. C. B., deBoer, A., \& Klunge, A. H. (2014). Exploring interaction effects in small samples increases rates of false-positive and false-negative findings: results from a systematic review and simulation study. Journal of Clinical Epidemiology, 67(7), 821-829.

Seibert, P. S., \& Ellis, H. C. (1991). A convenient self-referencing mood induction procedure. Bulletin of the Psychonomic Society, 29(2), 121-124.

Sheldon, K. M., \& Elliot, A. J. (1999). Goal striving, need satisfaction, and longitudinal well-being: the self-concordance model. Journal of personality and social psychology, 76(3), 482.

Soenens, B., Park, S. Y., Vansteenkiste, M., \& Mouratidis, A. (2012). Perceived parental psychological control and adolescent depressive experiences: A cross-cultural study with Belgian and South-Korean adolescents. Journal of Adolescence, 35, 261-272.

Soenens, B., \& Vansteenkiste, M. (2005). Antecedents and outcomes of self-determination in 3 life domains: The role of parents' and teachers' autonomy support. Journal of Youth and Adolescence, 34(6), 589-604. 
Soenens, B., Vansteenkiste, M., Goossens, L., Duriez, B., \& Niemiec, C. P. (2008). The intervening role of relational aggression between psychological control and friendship quality. Social Development, 17(3), 661-681.

Spielberger, C. D., Gorsuch, R. L., Lushene, R., Vagg, P. R., \& Jacobs, G. A. (1983). Manual for the State-Trait Anxiety Inventory. Palo Alto, CA: Consulting Psychologists Press.

Smith-Genthôs, K. R., Reich, D. A., Lakin, J. L., \& de Calvo, M. P. C. (2015). The tongue-tied chameleon: The role of nonconscious mimicry in the behavioral confirmation process. Journal of Experimental Social Psychology, 56, 179-182.

Soenens, B., \& Vansteenkiste, M. (2010). A theoretical upgrade of the concept of parental psychological control: Proposing new insights on the basis of self-determination theory. Developmental Review, 30(1), 74-99.

Swerts, M., \& Hirschberg, J. (2010). Prosodic predictors of upcoming positive or negative content in spoken messages. The Journal of the Acoustical Society of America, 128(3), 1337-1345.

Thompson, C. A., \& Prottas, D. J. (2006). Relationships among organizational family support, job autonomy, perceived control, and employee well-being. Journal of occupational health psychology, 11(1), 100.

Van Petegem, S., Beyers, W., Vansteenkiste, M., \& Soenens, B. (2012). On the association between adolescent autonomy and psychosocial functioning: Examining decisional (in)dependence from a self-determination theory perspective. Developmental Psychology, 48, 76-88.

Vandercammen, L., Hofmans, J., \& Theuns, P. (2014). The mediating role of affect in the relationship between need satisfaction and autonomous motivation. Journal of occupational and organizational psychology, 87(1), 62-79. 
Vansteenkiste, M., \& Ryan, R. M. (2013). On psychological growth and vulnerability: Basic psychological need satisfaction and need frustration as a unifying principle. Journal of Psychotherapy Integration, 23, 263-280.

Vansteenkiste, M., Ryan, R. M., \& Deci, E. L. (2008). Self-determination theory and the explanatory role of psychological needs in human well-being. In L. Bruni, F. Comim, \& M. Pugno (Eds.), Capabilities and happiness (pp. 187-223). Oxford: Oxford University Press.

Vansteenkiste, M., Simons, J., Lens, W., Sheldon, K. M., \& Deci, E. L. (2004). Motivating learning, performance, and persistence: The synergistic role of intrinsic goals and autonomy support. Journal of Personality and Social Psychology, 87, 246-260.

Vansteenkiste, M., Soenens, B., Van Petegem, S., \& Duriez, B. (2014). Longitudinal associations between adolescent perceived degree and style of parental prohibition and internalization and defiance. Developmental Psychology, 50(1), 229-236.

Watson, D., Clark, L. A., \& Tellegen, A. (1988). Development and validation of brief measures of positive and negative affect: The PANAS scale. Journal of Personality and Social Psychology, 54(6), 1063-1070.

Weinstein, N., Ed. (2014). Human motivation and interpersonal relationships: Theory, research, and applications. Dordrecht, NE: Springer.

Weinstein, N., \& Hodgins, H. S. (2009). The moderating role of autonomy and control on the benefits of written emotion expression. Personality and Social Psychology Bulletin, 35(3), $351-364$.

Weinstein, N., Hodgins, H. S., \& Ryan, R. M. (2010). Autonomy and nondefense in dyads: The effect of primed motivation on interaction quality and joint creative performance, Personality and Social Psychology Bulletin, 36, 12, 1603-1617. 
Weinstein, N., \& Ryan, R. M. (2010). When helping helps: An examination of motivational constructs underlying prosocial behavior and their influence on well-being for the helper and recipient. Journal of Personality and Social Psychology, 98, 2, 222-224.

Weinstein, N., \& Ryan, R. M. (2012). A motivational approach to stress response and adaptation. Stress \& Health, 1, 4-17.

Weinstein, N., Ryan, W. S., DeHaan, C. R., Przybylski, A. K., Legate, N., \& Ryan, R. M. (2012). Parental autonomy support and discrepancies between implicit and explicit sexual identities: Dynamics of self-acceptance and defense. Journal of Personality and Social Psychology, $102,815-832$.

Wilting, J., Krahmer, E., \& Swerts, M. (2006, September). Real vs. acted emotional speech. In Interspeech (Vol. 2006, p. 9th). 
Table 1

Main effects of covariates (gender, and country) on all acoustic indicators: Results from primary HLM models.

\begin{tabular}{|c|c|c|c|c|c|c|c|c|c|c|c|c|c|c|}
\hline & \multicolumn{8}{|c|}{ Study 1} & \multicolumn{6}{|c|}{ Study 2} \\
\hline & \multicolumn{2}{|c|}{ Gender } & \multicolumn{2}{|c|}{ Country } & \multicolumn{4}{|c|}{ Condition } & \multicolumn{2}{|c|}{ Gender } & \multicolumn{4}{|c|}{ Condition } \\
\hline & $b$ & $t$ & $b$ & $t$ & $b$ & $t$ & $r^{2}$ & $95 \% C I$ & $b$ & $t$ & $b$ & $t$ & $r^{2}$ & $95 \% C I$ \\
\hline Pitch mean & 95.35 & $14.18 * *$ & 9.09 & 1.28 & -9.63 & $-2.34^{*}$ & .017 & $-17.71,-1.55$ & 7.62 & $-6.92 * *$ & 7.62 & $5.50 * *$ & .040 & $4.91,10.33$ \\
\hline Pitch min & 74.38 & $14.32 * *$ & 13.60 & $2.61 *$ & -7.20 & $-2.96 * *$ & .027 & $-11.96,-2.44$ & 4.17 & $-11.53 * *$ & 4.17 & $4.23 * *$ & .025 & $2.25,6.09$ \\
\hline Pitch max & 15.34 & 0.93 & -17.53 & -1.42 & -27.57 & $-2.29 *$ & .015 & $-33.83,-7.91$ & -0.84 & $-4.01 * *$ & -0.84 & -0.28 & .000 & $-4.90,5.06$ \\
\hline Pitch range & 51.34 & 2.00 & 2.89 & 0.11 & -20.37 & -1.70 & .009 & $-43.91,3.17$ & -5.01 & -1.65 & -5.01 & -1.58 & .004 & $-11.20,1.18$ \\
\hline Intensity mean & -3.80 & $-2.81 * *$ & -13.21 & $-9.17 * *$ & -2.28 & $-4.21 * *$ & .050 & $-3.34,-1.22$ & -1.94 & $-4.76^{* *}$ & -1.94 & $-7.08 * *$ & .063 & $-2.47,-1.41$ \\
\hline Intensity min & -2.15 & -1.36 & -18.95 & $-9.97 * *$ & -1.15 & -1.71 & .009 & $-2.46,0.16$ & -0.48 & -0.003 & -0.48 & -1.30 & .002 & $-1.21,0.25$ \\
\hline Intensity max & -3.86 & $-2.45^{*}$ & -11.91 & $-7.48 * *$ & -2.40 & $-3.76^{* *}$ & .040 & $-1.15,-3.65$ & -3.22 & $-4.73 * *$ & -3.22 & $-9.03 * *$ & .101 & $-3.90,-2.56$ \\
\hline Intensity range & -1.71 & -1.30 & 7.03 & $5.06 * *$ & -1.25 & -1.89 & .011 & $-2.54,0.04$ & -2.74 & $-4.36^{* *}$ & -2.74 & $-8.84 * *$ & .096 & $-3.35,-2.13$ \\
\hline $0-500 \mathrm{~Hz}$ & -4.86 & $-3.29 * *$ & -12.47 & $-8.05^{* *}$ & -1.37 & $-2.10^{*}$ & .013 & $-2.64,-0.10$ & -1.87 & $-2.60^{*}$ & -1.87 & $-6.59 * *$ & .057 & $-2.42,-1.32$ \\
\hline $0-1000 \mathrm{~Hz}$ & -3.92 & $-2.48^{*}$ & -12.54 & $-7.75^{* *}$ & -2.23 & $-3.45 * *$ & .035 & $-3.50,-0.96$ & -2.23 & $-3.68 * *$ & -2.23 & $-7.51 * *$ & .073 & $-2.81,-1.63$ \\
\hline $500-1000 \mathrm{~Hz}$ & -2.17 & -1.24 & -12.80 & $-7.36^{* *}$ & -3.97 & $-5.72 * *$ & .090 & $-5.32,-2.62$ & -3.32 & $-6.70 * *$ & -3.32 & $-8.80 * *$ & .096 & $-4.07,-2.57$ \\
\hline $1000-5000 \mathrm{~Hz}$ & -6.38 & $-3.72 * *$ & -13.80 & $-8.30 * *$ & -3.22 & $-4.15^{* *}$ & .050 & $-4.75,-1.69$ & -4.29 & $-6.29 * *$ & -4.29 & $-9.76^{* *}$ & .115 & $-5.15,-3.43$ \\
\hline $5000-8000 \mathrm{~Hz}$ & -2.37 & -1.60 & -9.03 & $-5.80 * *$ & -1.10 & -1.60 & .008 & $-2.45,0.25$ & -1.92 & $-6.22 * *$ & -1.92 & $-6.00 * *$ & .046 & $-2.55,-1.29$ \\
\hline Speech rate & 0.001 & 0.11 & 0.03 & $4.81 * *$ & -0.00 & -1.46 & .006 & $-0.009,0.001$ & -0.01 & -1.27 & -0.01 & $-5.27 * *$ & .037 & $-0.017,-0.009$ \\
\hline
\end{tabular}

Note: $* p \leq .05, * * p<.01$.

The five indicators ranging from $0-8000 \mathrm{~Hz}$ refer to voice energy at different frequency bands. $+/-95 \%$ confidence intervals (CIs) based on $b$ values.

Autonomy was coded 2, control coded 1 . 
Table 2

Study 2 Main effects of prosody indicators on perceived support and pressure: Results from primary HLM models.

\begin{tabular}{lcccccc}
\hline & \multicolumn{3}{c}{ Support } & \multicolumn{3}{c}{ Pressure } \\
& $b$ & $t$ & $r^{2}$ & $b$ & $t$ & $r^{2}$ \\
\cline { 2 - 7 } Gender & -0.05 & -0.78 & .000 & 0.04 & 0.48 & .000 \\
Condition & 0.88 & 20.16 & .213 & -1.13 & -23.45 & .268 \\
$M$ Pitch & 0.00 & 0.54 & .000 & 0.00 & -0.96 & .001 \\
$M$ Intensity & -0.02 & $-2.85 * *$ & .006 & 0.03 & $3.19 * *$ & .006 \\
$0-1000 \mathrm{~Hz}$ & -0.02 & $-2.67 * *$ & .010 & 0.02 & $2.74 * *$ & .010 \\
Speech rate & -2.40 & $-7.12^{* *}$ & .033 & 2.97 & $8.49 * *$ & .046 \\
\hline
\end{tabular}

Notes: $* * p<.01$. Since reliability across all bands was $\alpha=.93$, an exploratory model using voice energy averaged bands showed a similar effect on support, $b=-.01, t(743)=-2.04, p=.03, d=-.11$, and defining averaged voice energy in the model did not impact direction or strength of other effects, $p s<.001$, for indicators other than mean pitch. 
Table 3

Correlations between Major Study Variables for Studies 3 (above the diagonal) and 4 (below the diagonal).

\begin{tabular}{|c|c|c|c|c|c|c|c|c|c|}
\hline & & 1 & 2 & 3 & 4 & 5 & 6 & 7 & 8 \\
\hline 1. & Condition & & -.08 & .06 & -.08 & .05 & -.12 & .08 & -- \\
\hline 2. & Support t1 & -.05 & & $.80 * *$ & $-.35 * *$ & $-.38 * *$ & $.48 * *$ & $.46^{* *}$ & -- \\
\hline 3. & Support t2 & $.24 * *$ & $.49 * *$ & & $-.38 * *$ & $-.46 * *$ & $.52 * *$ & $.61 * *$ & -- \\
\hline 4. & Pressure t1 & -.01 & $-.38 * *$ & $-.27 * *$ & & $.73 * *$ & $-.47 * *$ & $-.41 * *$ & -- \\
\hline 5. & Pressure $\mathrm{t} 2$ & $-.48 * *$ & -.08 & $-.60 * *$ & $.39 * *$ & & $-.57 * *$ & $-.61 * *$ & -- \\
\hline $6 s 3$ & Well-being $\mathrm{t} 1 *$ & -- & -- & -- & -- & -- & & $.83 * *$ & -- \\
\hline $7 \mathrm{~s} 3$. & Well-being t $2 *$ & -- & -- & -- & -- & -- & -- & & -- \\
\hline $6 s 4$ & Closeness $\mathrm{t} 1 *$ & -.00 & $.31 * *$ & $.24 * *$ & $-.28 * *$ & $-.17 *$ & -- & -- & \\
\hline $7 \mathrm{~s} 4$ & Closeness $\mathrm{t} 2 *$ & $.46^{* *}$ & .15 & $.39 * *$ & -.07 & $-.42 * *$ & $.45^{* *}$ & -- & -- \\
\hline $8 s 4$. & Prosocial beh. $\mathrm{t} 1 *$ & -.12 & $.21 *$ & .09 & $-.19 *$ & -.00 & $.39 * *$ & .04 & -- \\
\hline 9s4. & Prosocial beh. t2 & $.41 * *$ & .13 & $.33 * *$ & .03 & $-.39 * *$ & $.19 *$ & $.68 * *$ & $.30 * *$ \\
\hline
\end{tabular}

Notes. $* p<.05, * * p<.01$

*Well-being was assessed in Study 3 only (variables titled 6s3 and 7s3; in both cases s 3 refers to Study 3), whereas closeness and prosocial intention were only assessed in Study 4 (variables titled 6s4-9s4; in all cases 43 refers to Study 4). Under variable names, t1 = time 1 (baseline), $\mathrm{t} 2=$ time 2 (after intervention). 
Table 4

Studies 3 and 4 Main effects of Condition and of Baseline Levels of Outcomes.

\begin{tabular}{lcccccccc}
\hline & \multicolumn{4}{c}{ Baseline } & \multicolumn{5}{c}{ Condition } \\
\hline Study 3 & $\beta$ & $t, p$ & $d$ & $95 \%$ CI & $\beta$ & $t, p$ & $d$ & $95 \%$ CI \\
$\quad$ Support & .81 & $14.56,<.001$ & 2.75 & $.76, .99$ & .12 & $2.26, .03$ & 0.42 & $0.02,0.23$ \\
$\quad$ Pressure & .79 & $11.31,<.001$ & 2.14 & $.66, .93$ & -.01 & $-0.10, .92$ & -0.02 & $-0.15,0.16$ \\
$\quad$ Well-Being & .85 & $17.00,<.001$ & 3.21 & $.85,1.08$ & .18 & $3.57, .001$ & 0.67 & $0.46,1.61$ \\
Study 4 & & & & & & & & \\
$\quad$ Support & .51 & $7.27,<.001$ & 1.25 & $.51, .90$ & .27 & $3.84,<.001$ & 0.74 & $0.29,0.90$ \\
$\quad$ Pressure & .39 & $6.00,<.001$ & 1.06 & $.38, .75$ & -.48 & $-7.30,<.001$ & 1.22 & $-2.21,-1.27$ \\
Closeness & .45 & $7.08,<.001$ & 1.19 & $.45, .79$ & .46 & $7.19,<.001$ & 1.21 & $1.04,1.83$ \\
$\quad$ Prosocial behavior & .35 & $4.92,<.001$ & 0.83 & $.30, .71$ & .45 & $6.31,<.001$ & 1.06 & $0.91,1.74$ \\
\hline
\end{tabular}

Note. Cohen's $d$ (' $d$ ' in the table) represents effect size; 95\% CI is the 95\% confidence interval for $b$. 


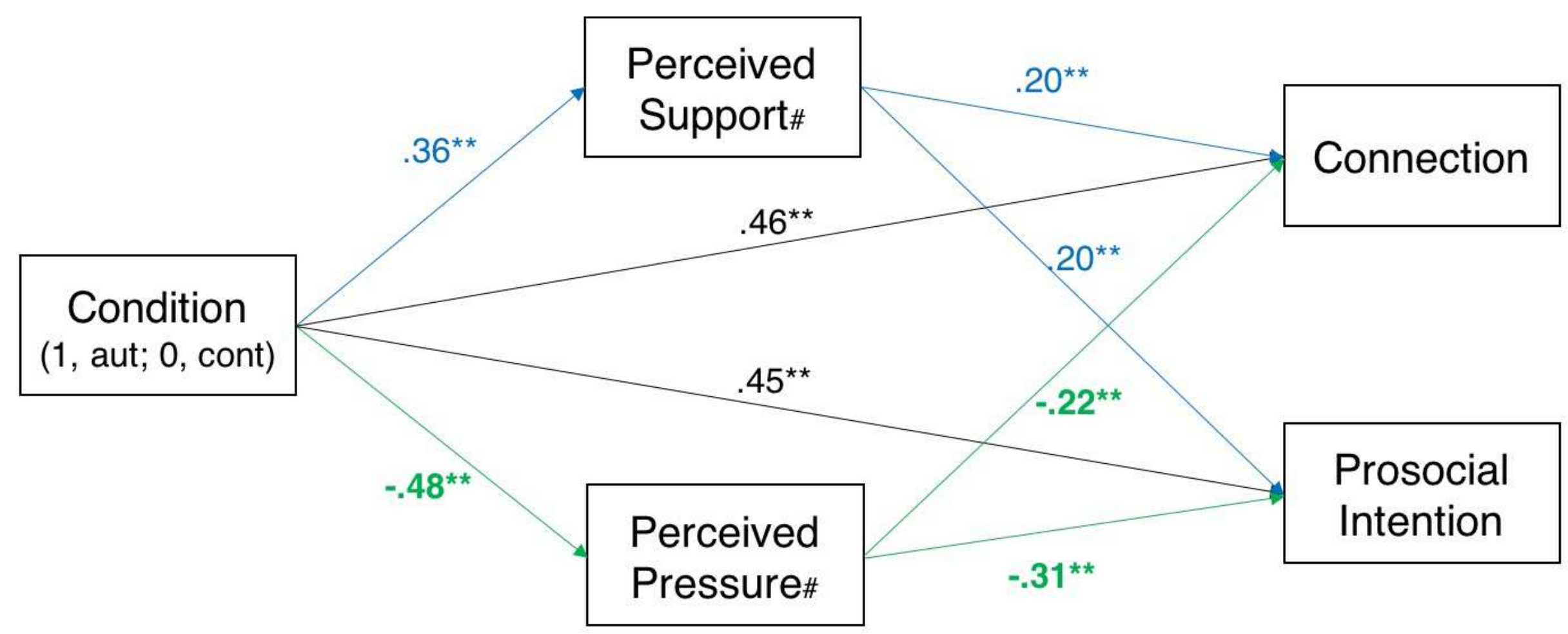

Figure 1. Study 4 condition effects on perceived support and pressure, and indirect effects on perceived connection and prosocial intention with respect to other students.

Notes: $* * p<.01$.

\#perceived pressure and support refers to state experiences of feeling supported and under pressure. 